\title{
LA SElección de CANDidatos en América LATina
}

\section{Candidate Selection in Latin America}

Pathways to Power: Political Recruitment and Candidate Selection in Latin America. Editado por Peter M. Siavelis y Scott Morgenstern. The Pennsylvania State University Press, 2008, $440 \mathrm{pp}$.

\section{RAFAEL PIÑEIRO}

Pontificia Universidad Católica de Chile

El periplo de la discusión académica sobre el funcionamiento de los regímenes presidencialistas en América Latina no ha hecho más que demostrar que no es suficiente apreciar las características institucionales de las relaciones entre poderes para entender el desempeño de estos sistemas. Para comprender el proceso político parece también necesario observar los efectos del sistema electoral sobre la fragmentación del sistema de partidos y sobre las conductas de los agentes políticos. Más recientemente se ha puesto de manifiesto la importancia de entender el impacto de la selección de candidatos y de las normas de funcionamiento parlamentario sobre los niveles de disciplina de los legisladores y sobre la vocación de los presidentes para conformar gobiernos de mayoría.

El libro editado por Siavelis y Morgenstern (2008) concurre a intentar explicar el rol del reclutamiento y la selección de candidatos tanto para los ejecutivos como para los legislativos en seis países de América Latina (Argentina, Brasil, Chile, Colombia, México y Uruguay). Este volumen representa un avance significativo para comprender la política en el continente, ya que comienza a echar luz respecto a aspectos sobre los que no se habían realizado esfuerzos de investigación sistemáticos. La empresa que acomete el libro -aunque exitosa- deja en claro los déficits de datos, investigación y sobre todo reflexión teórica sobre la política en América Latina. En particular sobre este último punto, cabe preguntarse si es posible este libro sin antes escribir un Why Parties y un Legislative Leviathan para América Latina, o si tanto uno como otro pueden adaptarse y viajar -sin dificultada los casos latinoamericanos.

En este sentido, Pathways to Power -al igual que Legislative Politics in Latin America-representa lo que se podría dar en llamar la última corriente de los estudios institucionalistas sobre la política en América Latina. Básicamente, su aspecto distintivo -respecto a la perspectiva anterior- es que intenta combinar variables institucionales y políticas, con el análisis de las ambiciones de los agentes, para explicar la política en Latinoamérica. En el caso del libro editado por Morgenstern y Nacif (2002) reconoce explícitamente la herencia de este enfoque característico de los estudios de American Politics sobre el Congreso de los Estados Unidos.

American Politics es una de las canteras teóricas y metodológicas más importantes para la política comparada, en particular para los análisis de la política en Latinoamérica. Sin 
embargo, a lo largo de ambos libros se aprecia con claridad cómo el desafío no estriba sólo en ejercicio de aplicar la teoría producida por los trabajos sobre las instituciones estadounidenses, sino en aportar nuevas reflexiones desde una nueva evidencia empírica. De esta forma, como se sugiere en Legislative Politics in Latin America lo que son supuestos dados en American Politics, se convierten en variables al analizar la política en América Latina. En consecuencia, las ambiciones de carrera de los legisladores ya no son estables como en Norteamérica sino crecientes, y el sistema electoral, los poderes presidenciales y la estructura del sistema de partidos dejan de verse como constantes y pasan a ser variables a analizar.

Tal vez es en la tarea de convertir los supuestos en variables -y luego rehacer un análisis agregado- en donde esta nueva corriente encuentra sus mayores problemas (más cuando algunas de estas variables varían incluso dentro de un mismo caso). Cuando se analiza empíricamente no parecen haber problemas en la definición de la unidad de análisis. Sin embargo, cuando se concluye y se intentan asignar determinadas características a las legislaturas de los países o al proceso político en general no hay una explicación sistemática de cómo se realiza el salto de características de los legisladores a características de las legislaturas.

En el caso de Pathways to Power el planteamiento teórico del libro tiene dos puntos fuertes. Primero, como ya dijimos, combina variables institucionales (fundamentalmente asociadas al sistema electoral) con variables políticas ligadas al funcionamiento de los partidos (centralización e inclusividad de los procesos de selección, organización partidaria, y manejo partidario del financiamiento político). Segundo, coloca al resultado del proceso de selección como variable dependiente, y también como variable independiente, en su relación con el comportamiento político de los candidatos. Aunque sobre esto último cabría preguntarse si en realidad "tipo de candidato" no es simplemente una construcción teórica que sólo facilita la comprensión de la verdadera conexión causal entre selección y conducta política.

Sin embargo, el enfoque también presenta algunos problemas. A modo de ejemplo: los tipos de candidato no parecen ser mutuamente excluyentes en lo que refiere a candidatos legislativos. Los casos de Chile y de Uruguay parecen demostrar que ser leal al partido (o a la fracción en el caso uruguayo) es compatible con brindar constituency service (ser leal también a los electores). Segundo -y asociado a lo anterior- el funcionamiento de la variable reelección no parece ajustarse a lo que describen los autores: síla reelección estimula la lealtad al partido, pero también en legisladores que son electos en circunscripciones pequeñas alienta -de la misma manera- el constituency service. En consecuencia, no es la variable reelección lo que parece importar para saber a quién son leales los candidatos, sino la capacidad del partido o de los votantes para controlar las carreras políticas, tengan estas por detrás ambiciones estáticas o crecientes. Estos problemas responden a que el capítulo teórico no logra sintetizar con éxito las variables y explicaciones que luego son testeadas por la mayoría de los capítulos sobre los casos concretos.

Asimismo, del capítulo introductorio se puede desprender que la unidad de análisis debe ser candidato. Esto no sólo porque -como sugieren los autores- en un mismo país los 
diferentes partidos pueden seleccionar de maneras diferentes, sino también porque dentro de un mismo país algunas de las variables relevantes -como por ejemplo la magnitud de la circunscripción- adquieren valores diferentes. En este sentido, si bien este no parece ser un problema para los artículos que tratan con la selección para cargos ejecutivos, sí se presentan contradicciones dentro de los capítulos que analizan la selección de candidatos para los legislativos, y este problema es peor aún, dentro del capítulo de conclusiones.

A pesar de estos problemas, es meritorio el esfuerzo que los autores realizan en el capítulo de conclusiones por rehacer -desde los diferentes análisis de los procesos de selección de candidatos para cargos legislativos y ejecutivos-, un análisis de cómo estos se combinan en cada país y dan lugar a formatos diferentes de relacionamiento entre ejecutivolegislativo.

Pathways to Power es un libro muy importante para entender las características del proceso político y de la competencia política en América Latina. Muestra la acumulación de la disciplina y en particular del enfoque neoinstitucionalista en los últimos veinte años en Latinoamérica. Sin embargo, por esto mismo también nos permite advertir los debes que -quienes analizan la política en el continente- tienen tanto en términos de investigación empírica, como -más importante aún- en la definición de modelos teóricos que respondan a las particularidades institucionales y políticas de los países del continente.

\section{REFERENCIAS}

Aldrich, John. 1995. Why Parties? Chicago: The University of Chicago Press.

Morgenstern, Scott and Benito Nacif (Ed.). 2002. Legislative Politics in Latin America. Cambridge: Cambridge University Press.

Cox, Gary W. y Mathew D. McCubbins. 1993. Legislative Leviathan: Party Government in the House. Berkeley y Los Angeles: University of California Press. 
